\title{
Anesthetic Technique (Sufentanil Versus Ketamine Plus Midazolam) and Quantitative Electroencephalographic Changes After Cardiac Surgery
}

\author{
Francois J. Smith MD*, Peter R. Bartel $\mathrm{PhD}^{\dagger}$, Johan M. Hugo MMed (Anes) and Pieter J. Becker $\mathrm{PhD}^{\ddagger}$ \\ ${ }^{\dagger}$ Department of Neurology, Pretoria Academic Hospital, School of Medicine, University of Pretoria, Pretoria, South Africa \\ ${ }^{\ddagger}$ Unit for Biostatistics, Medical Research Council of South Africa, Pretoria, South Africa. \\ * Department of Anaesthesiology, Pretoria Academic Hospital, School of Medicine, University of Pretoria, Pretoria, South Africa
}

Objectives: Cardiac surgery involving cardiopulmonary bypass is associated with neurologic deterioration. Several interventions, including anesthetic techniques, have been designed to limit ischemic brain damage and have been evaluated in animals. Markers of neurologic injury may facilitate the assessment of these interventions in humans.

Design: A blinded randomized prospective study comparing 2 anesthetic techniques (one sufentanilbased, the other ketamine and midazolam-based) in patients undergoing cardiac surgery. Quantitative electroencephalography was used to detect postoperative neurologic injury.

Setting: Major teaching hospital.

Participants: Forty-two patients aged 18 to 70 years undergoing cardiac surgery.

Interventions: Patients were anesthetized with either a sufentanil-based or a ketamine and midazolambased technique for cardiac surgery with cardiopulmonary bypass. Quantitative electroencephalography was performed preoperatively as well as 5 to 6 days postoperatively.

Measurements and Main Results: Quantitative electroencephalography outcome did not differ $(p>0.05)$ between the 2 groups. It showed significant deterioration between preoperative and postoperative assessments with a decrease in faster and an increase in slower frequencies. In addition, the alpha attenuation index decreased. This may reflect a decrease in alertness. Both the intergroup comparisons and the assessment of individual changes failed to reveal significant differences between the anesthetic techniques. The adjuvant use of isoflurane correlated with less deterioration of quantitative electroencephalographic variables.

Conclusions: The use of either sufentanil-based or ketamine and midazolam-based anesthetic techniques for cardiac surgery with cardiopulmonary bypass had no effects on a marker of postoperative neurologic injury (ie, quantitative electroencephalography).

THE MANIFESTATIONS of cerebral injury after cardiac surgery, to some extent ascribable to the effects of cardiopulmonary bypass (CPB), include postoperative delirium, stroke, and cognitive changes. ${ }^{1}$ Potential methods to identify neurologic injury include clinical examination, neuropsychologic testing, electroencephalographic (EEG) changes, magnetic resonance imaging, and chemical markers.

The neuroprotective properties of ketamine have been shown in animals ${ }^{2}$ but have not, to the authors' knowledge, been confirmed in humans. Ketamine binds to the phencyclidine area on the N-methyl-Daspartate (NMDA) receptor complex and inhibits $\mathrm{Na}^{+}$and $\mathrm{Ca}^{2+}$ influx through NMDA-associated ion channels. $^{3}$ Opioids may also protect the brain by decreased cerebral oxygen consumption, noncompetitive NMDA antagonism, ${ }^{4}$ or hypoxic preconditioning. ${ }^{5}$ The $\mathrm{GABA}_{\mathrm{A}}$ agonist midazolam has been shown to be neuroprotective in animals. ${ }^{6}$ Ketamine, like other NMDA-receptor antagonists, may be neurotoxic to the posterior gyrus cinguli and retrosplenic cortex. $M_{1}$ anticholinergic drugs and $\mathrm{GABA}_{A}$ agonists like benzodiazepines prevent this effect. ${ }^{7}$ 
Toner et $\mathrm{al}^{8}$ and Chabot et $\mathrm{al}^{9}$ have shown that quantitative electroencephalography (QEEG) changes correlated with neuropsychologic deterioration after cardiac surgery. Chabot et $\mathrm{al}^{9}$ found that patients whose neuropsychologic performance remained stable 1 week after CPB were correctly classified by the changes in the 1 week postoperative QEEG, with a specificity of $78.9 \%$, and those whose neuropsychologic performance deteriorated, with a sensitivity of $87.6 \%$. The respective specificity and sensitivity of the 1-week postoperative QEEG and neuropsychologic deterioration 3 months postoperatively were $87 \%$ and $100 \%$. The alpha attenuation index (AAI) is an index of EEG reactivity and its deterioration may indicate reduced alertness; it has been related to reduced performance in tasks requiring vigilance. ${ }^{10}$ An advantage of electrophysiologic testing with the QEEG is that it, unlike neuropsychologic evaluation, does not require literacy and motivation.

No previous human studies have compared a sufentanil-based anesthetic technique with a ketamine and midazolam-based technique in terms of markers of neurologic injury after cardiac surgery. The aim of this study was to compare the preoperative and postoperative QEEG changes in patients receiving either a sufentanil-based or a ketamine and midazolam-based anesthetic for cardiac surgery with CPB.

\section{Methods}

The study was performed with institutional ethics committee approval and written informed consent. Patients, surgeons, CPB technologists, those performing and analyzing the QEEG, and the data analyst were blinded regarding the anesthetic technique. The same anesthesiologist administered all the anesthetics and was not blinded to the prescribed anesthetic technique. The cohort consisted of 42 patients; 21 for coronary artery bypass graft (CABG) surgery and 21 for valve replacement surgery. The $21 \mathrm{CABG}$ and the 21 valve replacement patients were randomized (by the statistician) separately to receive either sufentanil or ketamine plus midazolam as the primary anesthetic technique. Patients aged 18 to 70 years scheduled for elective first-time cardiac surgery were included. An ejection fraction $<40 \%$, psychosis, active neurologic disease, carotid artery bruits, a history of syncope, a transient ischemic neurologic deficit, a previous cerebrovascular accident, renal failure (serum urea $>10 \mathrm{mmol} / \mathrm{L}$ or serum creatinine $>180 \mu \mathrm{mol} / \mathrm{L}$ ), liver disease, known diabetes mellitus, or a random blood glucose $>11.1$ $\mathrm{mmol} / \mathrm{L}$ excluded a patient from the study.

The doses of midazolam, ketamine, and sufentanil were based on those reported in the literature. ${ }^{11,12,13}$ and 14 These doses have been proposed to ensure a sufficient depth of anesthesia and may, but are not intended to, be neuroprotective. Patients received an oral dose of midazolam of $0.2 \mathrm{mg} / \mathrm{kg} 2$ hours preoperatively. Those in the sufentanil group were induced with sufentanil, $0.7 \mu \mathrm{g} / \mathrm{kg} / \mathrm{min}$, until loss of responsiveness to a command to keep their eyes open or a minimum dose of $2 \mu \mathrm{g} / \mathrm{kg}$. This was followed by sufentanil, $3 \mu \mathrm{g} / \mathrm{kg} / \mathrm{h}$. In the ketamine-midazolam group, patients received $15 \mu \mathrm{g} / \mathrm{kg}$ of alfentanil before induction with ketamine, $0.7 \mathrm{mg} / \mathrm{kg} / \mathrm{min}$, plus midazolam, $70 \mu \mathrm{g} / \mathrm{kg} / \mathrm{min}$, until loss of consciousness, or minimum doses of 2.0 and $0.2 \mathrm{mg} / \mathrm{kg}$, respectively. This was followed by ketamine, 2 $\mathrm{mg} / \mathrm{kg} / \mathrm{h}$, plus midazolam, $0.2 \mathrm{mg} / \mathrm{kg} / \mathrm{h}$. After induction of anesthesia, patients were paralyzed with vecuronium, $0.15 \mathrm{mg} / \mathrm{kg}$. Isoflurane was administered as an adjuvant anesthetic in both groups. Administration of isoflurane and vecuronium were guided by clinical observations.

The surgeon palpated the aorta to determine the sites of cannulation and grafting. Echocardiographic examination of the aorta was not done. The procedures were performed during hypothermic (nasopharyngeal temperature $30^{\circ} \mathrm{C}$ ) nonpulsatile (Cobe roller pump; Cobe, Lakewood, CO) CPB. The pump circuit was primed with crystalloid $\left(\mathrm{Na}^{+} 130 \mathrm{mmol} / \mathrm{L}, \mathrm{K}^{+} 4 \mathrm{mmol} / \mathrm{L}, \mathrm{Mg}^{2+} 1.5 \mathrm{mmol} / \mathrm{L}, \mathrm{HCO}_{3}{ }^{-} 27\right.$ $\mathrm{mmol} / \mathrm{L}, \mathrm{Cl}^{-} 110 \mathrm{mmol} / \mathrm{L}$ ). A membrane oxygenator (Monolyth-Pro oxygenator and reservoir; Sorin

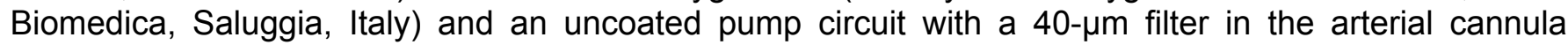
(Dideco perfusion tubing systems; Sorin Biomedica) were used. Patients were heparinized with heparin, $500 \mathrm{lU} / \mathrm{kg}$. The activated coagulation time was kept $>400$ seconds. Blood pressure during CPB was kept between 50 and $70 \mathrm{mmHg}$. At pressures $<50 \mathrm{mmHg}$, pump flow was increased up to $4 \mathrm{~L} / \mathrm{min} / \mathrm{m}^{2}$ after which phenylephrine was given. ${ }^{15}$ Hypertension was treated by lower flows and the addition of isoflurane to the pump fresh gas. Anterograde cold $\left(4^{\circ} \mathrm{C}\right)$ crystalloid cardioplegia was used in all patients. Cardiotomy suction blood was returned to the pump. Rewarming was active with a maximum temperature of $38^{\circ} \mathrm{C}$ in the heat exchanger. Epinephrine, nitroglycerin, phenylephrine, and volume expanders were used as considered necessary. 
Using the $\alpha$-stat blood gas strategy, normocapnia $\left(\mathrm{PaCO}_{2} 31-39 \mathrm{mmHg}\right.$ at this altitude) was maintained throughout the procedure. End-tidal $\mathrm{PCO}_{2}$ was monitored before and after CPB but not during CPB. Isoflurane concentration (\%) was monitored in the end-tidal gas before and after CPB and in the fresh gas flow (dial reading) during CPB.

A QEEG was obtained 1 to 2 days preoperatively and repeated 5 or 6 days postoperatively. This was in accordance with Chabot et $\mathrm{al}^{9}$ who repeated the QEEG 1 week postoperatively. Multiple-channel EEG recordings with a digitizing rate of $200 \mathrm{~Hz}$ were performed using a $\mathrm{Cz}$ reference. Artifacts and any periods of drowsiness were excluded from the analysis. Fast Fourier transform was applied off-line using EEGFOCUS version 2.0 software (MEGIS Software, $\mathrm{GmbH}$, Munich, Germany). The epoch length was 2.6 seconds, and the bandpass was set at 1.6 to $30 \mathrm{~Hz}$. The results were summed into 4 frequency bands: delta 1.6 to $4 \mathrm{~Hz}$, theta 4 to $8 \mathrm{~Hz}$, alpha 8 to $13 \mathrm{~Hz}$, and beta 13 to $35 \mathrm{~Hz}$. Results were expressed on an amplitude $(\mu \mathrm{V})$ scale. The absolute value for each frequency band was used to derive the relative amplitude expressed as a percentage. In addition to the alpha/theta amplitude ratio, the AAI was calculated. The peak frequency of the amplitude spectrum (PS) $>2 \mathrm{~Hz}$ was included. The PS of the amplitude spectrum was automatically determined and visually confirmed. The AAI was obtained by dividing the alpha amplitude with eyes closed by the alpha amplitude with eyes opened to provide an index of the reactivity of the EEG. In the current study, analysis was confined to parieto-occipital EEG changes because these changes have been reported to be particularly sensitive to the effects of cardiac surgery. ${ }^{16 \text { and } 17}$

The percentage change in a QEEG parameter was calculated for each patient: $\Delta x \%=(x$ postoperative $/ x$ preoperative - 1)100. A decrease and an increase in the relative $\%$ of the higher frequencies (beta amplitude, alpha amplitude), alpha/theta ratio, PS, and AAI were expressed as negative and positive values, respectively. An increase and decrease in the relative delta and theta amplitudes were expressed as negative and positive changes, respectively. The criterion for deterioration of an EEG parameter was an increase of $\geq 20 \%$ of delta or theta or a decrease of $\geq 20 \%$ of alpha, beta, PS, alpha/theta ratio or AAI. At least 2 of these criteria had to be met to determine EEG deterioration. These criteria are similar to those applied by Toner et al. ${ }^{8} \mathrm{~A}$ clinical neurologic examination was performed preoperatively and before discharge; patients were also questioned about intraoperative awareness.

Continuously monitored parameters (eg, blood pressure, heart rate, temperature, isoflurane concentration) were recorded every 5 minutes. For both the continuous and intermittent measurements (blood gas analysis), means and medians (where applicable) of all the recorded values over time were determined. Because there were only minor differences between means and medians, the former were used. Total doses of drugs were recorded.

Calculation of the sample size was based on the primary aim; the determination of the influence of the anesthetic technique on a marker of neurologic injury, the QEEG; or, the detection of whether treatment groups differ with respect to change from a baseline. A difference of $20 \%$ between groups, with respect to a change from baseline, was regarded as clinically relevant. The standard deviation of change from baseline was set to $20 \%{ }^{18}$ (ie, the range of change in individual patients as expected from $10 \%$ to $90 \%$ ). This approximates 4 standard deviations. Based on these assumptions, a sample of 42 patients (21 per group, balanced for each type of operation) had a power to detect such a difference in excess of $85 \%$ at the 0.05 level of significance using a 2-sample $t$ test. The paired $t$ test was used for changes in all patients. Categoric data were compared using the 2-sided Fisher exact test. $\mathrm{H}_{0}$ was rejected at the 0.05 level of significance when $p \leq 0.05$. Correlations were done using the Spearman correlation coefficient $(\rho)$.

\section{Results}

Data are presented as means \pm standard deviation. There were neither double valve replacements nor valve replacement combined with CABG surgery. There were 10 valve replacements and 11 CABG patients in the sufentanil group and 11 valve replacements and 10 CABG patients in the ketaminemidazolam group. Preoperative and intraoperative findings are summarized in Table 1. 
Table 1. Descriptive Statistics for Pre- and Intraoperative Variables (Means \pm SD)

\begin{tabular}{|c|c|c|c|}
\hline Variable & Sufentanil & $\begin{array}{l}\text { Ketamine- } \\
\text { Midazolam }\end{array}$ & $p$ \\
\hline Age (y) & $47 \pm 14$ & $47 \pm 12$ & NS \\
\hline Body mass (kg) & $76 \pm 20$ & $79 \pm 16$ & NS \\
\hline Mitral and aortic valve replacements & 9 and 1 & 8 and 3 & NS \\
\hline CABG & 11 & 10 & NS \\
\hline \multicolumn{4}{|l|}{ Time (min) } \\
\hline Before CPB & $57 \pm 21$ & $56 \pm 25$ & NS \\
\hline CPB & $76 \pm 22$ & $79 \pm 21$ & NS \\
\hline After CPB & $58 \pm 11$ & $58 \pm 10$ & NS \\
\hline Ejection fraction (\%) & $61 \pm 12$ & $59 \pm 11$ & NS \\
\hline \multicolumn{4}{|l|}{ Mean blood pressure $(\mathrm{mmHg})$} \\
\hline Before CPB & $77 \pm 10$ & $85 \pm 14$ & 0.0242 \\
\hline During CPB & $58 \pm 8$ & $57 \pm 6$ & NS \\
\hline After CPB & $72 \pm 13$ & $77 \pm 7$ & NS \\
\hline Pump flow (L/min/m²) & $3.1 \pm 0.4$ & $2.9 \pm 0.3$ & NS \\
\hline Peripheral resistance during CPB (dyne/s/ $\mathrm{cm}^{5} / \mathrm{m}^{2}$ ) & $1557 \pm 298$ & $1578 \pm 265$ & NS \\
\hline \multicolumn{4}{|l|}{ Central venous pressure $(\mathrm{mmHg})$} \\
\hline Before CPB & $7 \pm 3$ & $7 \pm 3$ & NS \\
\hline After CPB & $9 \pm 3$ & $10 \pm 3$ & NS \\
\hline Isoflurane (\%) during whole procedure & $0.12 \pm 0.10$ & $0.18 \pm 0.19$ & NS \\
\hline Number of patients who received isoflurane & $11 / 21$ & $10 / 21$ & NS \\
\hline \multicolumn{4}{|l|}{ End-tidal $\mathrm{PCO}_{2}(\mathrm{mmHg})$} \\
\hline Before CPB & $32 \pm 2$ & $30 \pm 2$ & 0.0281 \\
\hline After CPB & $33 \pm 2$ & $32 \pm 3$ & NS \\
\hline \multicolumn{4}{|l|}{$\mathrm{PaCO}_{2}(\mathrm{mmHg})$} \\
\hline Before CPB & $34 \pm 5$ & $34 \pm 4$ & NS \\
\hline During CPB & $34 \pm 3$ & $33 \pm 3$ & NS \\
\hline After CPB & $36 \pm 4$ & $35 \pm 4$ & NS \\
\hline Blood glucose during CPB (mmol/L) & $6.8 \pm 1.5$ & $7.3 \pm 1.3$ & NS \\
\hline \multicolumn{4}{|l|}{ Core temperature $\left({ }^{\circ} \mathrm{C}\right)$} \\
\hline Before CPB & $36.1 \pm 0.4$ & $35.6 \pm 0.5$ & 0.0009 \\
\hline During CPB & $32.1 \pm 1.2$ & $32.4 \pm 2.0$ & NS \\
\hline Maximum during CPB & $37.3 \pm 0.5$ & $37.3 \pm 0.3$ & NS \\
\hline After CPB & $36.1 \pm 0.4$ & $36.4 \pm 0.6$ & 0.0451 \\
\hline \multicolumn{4}{|l|}{ Hematocrit (\%) } \\
\hline Before CPB & $38 \pm 3$ & $37 \pm 6$ & NS \\
\hline During CPB & $29 \pm 4$ & $26 \pm 5$ & 0.0252 \\
\hline Minimum during $\mathrm{CPB}$ & $28 \pm 4$ & $24 \pm 5$ & 0.0089 \\
\hline After CPB & $30 \pm 4$ & $29 \pm 4$ & NS \\
\hline \multicolumn{4}{|l|}{ Fluid balance (mL/kg) } \\
\hline Crystalloid & $47 \pm 16$ & $43 \pm 19$ & NS \\
\hline Colloid & $0.6 \pm 1.8$ & $0.3 \pm 1.3$ & NS \\
\hline Blood transfusion & $5 \pm 6$ & $5 \pm 6$ & NS \\
\hline Blood loss & $9 \pm 3$ & $8 \pm 2$ & NS \\
\hline Blood transfusion/blood loss ratio & $0.7 \pm 0.7$ & $0.5 \pm 0.6$ & NS \\
\hline Urine output (mL/h) & $18 \pm 10$ & $22 \pm 16$ & NS \\
\hline
\end{tabular}

Abbreviation: NS, not significant.

The mean arterial blood pressure was significantly lower in the sufentanil group than in the ketaminemidazolam group before CPB $(77 \pm 10 \mathrm{mmHg}$ and $85 \pm 14 \mathrm{mmHg}$, respectively; $p=0.0242)$. $\mathrm{PaCO}_{2}$ did not differ significantly between groups during any of the stages of surgery. End-tidal $\mathrm{PCO}_{2}$ before $\mathrm{CPB}$ 
was (statistically) significantly higher in the sufentanil than in the ketamine-midazolam group (32 \pm 2 $\mathrm{mmHg}$ and $30 \pm 2 \mathrm{mmHg}$, respectively; $p=0.0281$ ) but did not differ significantly after CPB.

There were no significant differences between anesthetic techniques regarding transfusion of blood and other fluids, blood loss, and urinary output. The hematocrit was higher in the sufentanil than in ketaminemidazolam group during CPB $(29 \% \pm 4 \%$ and $26 \% \pm 5 \%$, respectively; $p=0.0252)$.

The core temperature (nasopharynx) of all patients during CPB was $32.2^{\circ} \pm 1.6^{\circ} \mathrm{C}$ and did not differ between groups. Before CPB, core temperatures were significantly higher in the sufentanil group than in the ketamine-midazolam group $\left(36.1^{\circ} \pm 0.5^{\circ} \mathrm{C}\right.$ and $35.6^{\circ} \pm 0.4^{\circ} \mathrm{C}$, respectively; $\left.p=0.0009\right)$. After $\mathrm{CPB}$, the temperatures were significantly lower in the sufentanil than in ketamine-midazolam group $\left(36.1^{\circ} \pm\right.$ $0.4^{\circ} \mathrm{C}$ and $36.4^{\circ} \pm 0.6^{\circ} \mathrm{C}$, respectively; $p=0.0451$ ).

There was no significant difference between the 2 groups regarding the mean isoflurane concentration administered or the number of patients who received isoflurane. In all patients, the concentration of isoflurane administered during the whole operation was $0.15 \% \pm 0.15 \%$ and during CPB $0.10 \% \pm 0.15 \%$. There were also no differences between the groups regarding the mean doses of cardiac drugs (Table 2).

Table 2. Drugs Administered Intraoperatively (Means \pm SD)

\begin{tabular}{|c|c|c|c|}
\hline Variable & Sufentanil & Ketamine-Midazolam & $p$ \\
\hline Epinephrine total dose $(\mu \mathrm{g} / \mathrm{kg})$ & $4 \pm 2$ & $4 \pm 1$ & NS \\
\hline Number of patients who received epinephrine & $21 / 21$ & $21 / 21$ & NS \\
\hline Nitroglycerin total dose $(\mu \mathrm{g} / \mathrm{kg})$ & $10 \pm 9$ & $11 \pm 9$ & NS \\
\hline Number of patients who received nitroglycerin & $19 / 21$ & $20 / 21$ & NS \\
\hline Phenylephrine $(\mu \mathrm{g} / \mathrm{kg})$ & $1 \pm 1$ & $1 \pm 1$ & NS \\
\hline \multicolumn{3}{|l|}{ Isoflurane concentration (\%) administered } & NS \\
\hline During whole procedure & $0.12 \pm 0.10$ & $0.18 \pm 0.19$ & NS \\
\hline During CPB & $0.09 \pm 0.14$ & $0.11 \pm 0.17$ & NS \\
\hline \multicolumn{4}{|l|}{ Number of patients who received isoflurane } \\
\hline During whole procedure & $11 / 21$ & $10 / 21$ & NS \\
\hline During CPB & $7 / 21$ & $9 / 21$ & NS \\
\hline
\end{tabular}

Abbreviation: NS, not significant.

There were no significant differences in preoperative QEEG variables between the 2 groups of patients; nor were there significant differences in the percentage change between the groups (Table 3). QEEG deterioration ( $\geq 2$ parameters deteriorating $\geq 20 \%$ ) did not differ between the sufentanil and ketaminemidazolam groups (14/21 [66.67\%] and 13/21 [61.90\%], respectively; $p=0.5000)$.

Table 3. Percentage Changes (Means \pm SD) Between the Baseline and Postoperative Assessments in QEEG Variables in the Sufentanil $(n=21)$ and Ketamine-Midazolam $(n=21)$ Groups

\begin{tabular}{|c|c|c|c|}
\hline Variable & Sufentanil & Ketamine-Midazolam & $p$ \\
\hline$\Delta$ beta $\%$ & $-12.36 \pm 14.2$ & $-12.64 \pm 11.1$ & 0.9434 \\
\hline$\Delta$ alpha $\%$ & $-2.1 \pm 24.4$ & $-4.3 \pm 15.3$ & 0.7346 \\
\hline$\Delta$ delta $\%$ & $-25.6 \pm 40.4$ & $-24.9 \pm 31.3$ & 0.9485 \\
\hline$\Delta$ theta $\%$ & $-26.2 \pm 22.8$ & $-21.3 \pm 22.8$ & 0.4936 \\
\hline$\Delta$ alpha/theta $\%$ & $-18.4 \pm 33.7$ & $-18.2 \pm 21.2$ & 0.9821 \\
\hline$\triangle \mathrm{PS} \%$ & $-4.8 \pm 15.2$ & $-8.3 \pm 13.4$ & 0.4474 \\
\hline$\triangle \mathrm{AAI} \%$ & $-14.9 \pm 32.7^{*}$ & $-25.7 \pm 23.0 \dagger$ & 0.2225 \\
\hline
\end{tabular}

Abbreviations: $\Delta$ alpha\%, percentage change of relative alpha; PS, peak spectrum. The same for relative beta, relative delta, relative theta, alpha/theta $\%$, and alpha attenuation index (AAI).

$$
\begin{aligned}
& { }^{*} n=19 . \\
& { }^{\dagger} n=20 .
\end{aligned}
$$


Sixty-four percent of all patients (27) showed QEEG deterioration; in 29\% (12), it was unchanged; and in $7 \%$ (3), it was improved: 2 in the ketamine-midazolam group and 1 in the sufentanil group. The mean values of all parameters deteriorated significantly, but the largest changes were observed in the following: $\Delta$ delta $\%=-25 \% \pm 36 \%(p<0.0001), \Delta$ theta $\%=-24 \% \pm 23 \%(p<0.0001)$, and $\Delta$ AAI $\%=$ $-20 \% \pm 28 \%(p=0.0007)$. The $\Delta$ beta $\%$ was $-13 \% \pm 13 \%(p<0.0001), \Delta$ alpha $\%=-3 \% \pm 20 \%(p=$ $0.0282), \Delta$ alpha/theta $\%=-18 \% \pm 28 \%(p<0.0001)$, and $\Delta$ PS $\%=-7 \% \pm 14 \%(p=0.0063)$. The alpha attenuation index decrease probably reflects a decrease in alertness. ${ }^{10}$ In 2 patients, a preoperative, and, in 1 patient a postoperative, spectral peak could not be identified, apparently because of the absence of a dominant alpha rhythm.

No significant correlation was found between any of the changes in QEEG variables and age, CPB time, intraoperative blood pressure, hematocrit, temperature, or $\mathrm{PaCO}_{2}$. There were significant correlations between the mean isoflurane concentration measured during the whole operation and $\Delta$ beta $\%(\rho=0.46$, $p=0.0033), \Delta$ theta $\%(\rho=0.50, p=0.0015), \Delta$ alpha/theta $\%(\rho=0.34, p=0.0363)$, and $\Delta \mathrm{PS} \%(\rho=0.33$, $p=0.0395)$.

No patient suffered any neurologic deficit or delirium as determined with a clinical physical examination postoperatively. Neither implicit nor explicit intraoperative awareness was reported.

\section{Discussion}

The main finding of this study was that QEEG changes did not differ significantly between sufentanilbased compared with ketamine and midazolam-based anesthetic techniques, both in respect to mean change and in the percentage of individual subjects showing significant deterioration. The QEEG deteriorated in $64 \%$ of all patients. The pattern of deterioration in respect to specific QEEG parameters, such as increases in relative delta and theta frequencies, as well as decreases in AAI and PS, are similar to those reported by Chabot et al. ${ }^{9}$ The reason for improvement of the QEEG in 3 patients is not clear.

The assessment of postoperative cognitive function has been reviewed by Rasmussen et al. ${ }^{19}$ The notion of $20 \%$ or 1 standard deviation deterioration in $20 \%$ of a battery of neuropsychologic tests as representing a significant change has been applied by Newman et $\mathrm{al}^{18}$ and Stump. ${ }^{20}$ The present authors are of the opinion that criteria for "significant change" may also be applied to markers such as the QEEG. Therefore, in this study, it was decided to regard a deterioration of $\geq 20 \%$ in 2 or more of 7 QEEG variables as the criterion of significant deterioration, which is similar to the criterion set by Toner et al. ${ }^{8}$

In this study, no sedative drugs (including opioids) were allowed for at least 24 hours before the preoperative and postoperative QEEG. It is therefore unlikely that residual effects of anesthesia, sedatives, or opioids affected the EEG 5 to 6 days postoperatively. Sleep deprivation could be a cause of some deterioration in QEEG parameters. Patients were questioned about sleep disturbances but did not report any. The EEG was carefully scrutinized for any signs of drowsiness, including changes in frequency of the EEG, and for occurrence of slow rolling eye movements. Any sections containing these changes were excluded from analysis.

Part of the explanation for the lack of difference between the effects of sufentanil and ketaminemidazolam on QEEG changes may be that both possess anti-NMDA properties. Other brain protective measures (hypothermia and isoflurane) might also have offered significant protection in both groups.

A post hoc finding of this study was the significant correlation between the mean isoflurane concentration and $\Delta$ beta $\%, \Delta$ theta $\%, \Delta$ alpha/theta $\%$, and $\Delta \mathrm{PS} \%$. The concentration of isoflurane administered during the whole operation $(0.18 \% \pm 0.14 \%)$ and during CPB $(0.10 \% \pm 0.15 \%)$ was substantially less than 1 minimum alveolar concentration (1.2\%) and did not differ significantly between the 2 groups. Apart from decreasing cerebral oxygen consumption, isoflurane may be neuroprotective by decreasing glutamate release ${ }^{21}$ by suppressing the increase of extracellular dopamine during cerebral ischemia, ${ }^{22}$ or by preserving hippocampal $\mathrm{Ca}^{2+} /$ calmodulin-dependent protein kinase. ${ }^{23}$ 
Several intraoperative variables have been implicated in the production of changes in the markers of neurologic injury after cardiac surgery. Apart from blood pressure before $\mathrm{CPB}$, end-tidal $\mathrm{PCO}_{2}$ before $\mathrm{CPB}$, temperature before and after CPB, and hematocrit during CPB, none of these variables differed significantly between groups (Table 1). Patients in both groups were relatively young (47 \pm 14 years and $47 \pm 12$ years), which may explain the lack of difference in QEEG changes.

The significantly higher blood pressure before CPB in the ketamine-midazolam group $(85 \pm 14 \mathrm{mmHg} v$ $77 \pm 10 \mathrm{mmHg}$ ) may be explained by the maintenance of neural responses to hypotension during ketamine anesthesia. ${ }^{24}$ An explanation for the lower hematocrit in the ketamine-midazolam group during CPB is not clear because the fluid balance did not differ between groups. Neither volume of blood transfused, blood loss, blood loss/transfusion ratio, nor volume of other intravenous fluids or urinary output differed significantly between these groups during any of the stages of the operations. The explanation may lie in the systemic inflammatory response that accompanies CPB, which may contribute to loss of intravascular fluid to the interstitial space. This fluid shift may bring about hemoconcentration. Ketamine is antiinflammatory because of suppression of nuclear factor $\mathrm{kB}$ expression at clinically relevant concentrations. ${ }^{25}$ Nuclear factor $\mathrm{KB}$ is involved in the transcription of several genes, including those encoding the proinflammatory cytokines tumor necrosis factor $\alpha$, interleukin 6 , and interleukin $8 .{ }^{26}$

At this institution, CPB is performed at a target temperature of about $30^{\circ} \mathrm{C}$ with rewarming to normothermia. Using jugular bulb oxygen saturation, Shaaban $\mathrm{et}^{\mathrm{al}}{ }^{27}$ could not show a difference in brain oxygenation between CPB at $28^{\circ} \mathrm{C}$ and $34^{\circ} \mathrm{C}$. Temperature was significantly higher in the sufentanil group before CPB $\left(36.1^{\circ} \pm 0.4^{\circ} \mathrm{C} v 35.6^{\circ} \pm 0.5^{\circ} \mathrm{C}, p=0.0007\right)$ but lower after CPB $\left(36.1^{\circ} \pm 0.4^{\circ} \mathrm{C} v 36.4^{\circ}\right.$ $\pm 0.6^{\circ} \mathrm{C}, p=0.0323$ ). Because both groups were close to normothermia after $\mathrm{CPB}$, these small differences were probably not significant from a neuroprotective point of view.

Neurologic outcome may not only be influenced by the anesthetic technique and surgical and CPB practice, but also by postoperative care. Patients may sustain further brain damage postoperatively because they are often cardiovascularly unstable and warm. Browne et $a^{28}$ have shown a significant correlation between hypoxemia 5 days postoperatively after cardiac surgery and cognitive decline. In this study, postoperative care of the patients was not controlled, which might have had an equalizing influence on outcome.

It is uncertain whether a favorable neuropsychologic outcome excludes neurologic impairment. ${ }^{29}$ Diffusion-weighted magnetic resonance imaging has shown new brain lesions after cardiac surgery that were not reflected by persistent neurocognitive decline.$^{30}$ Chabot et $\mathrm{al}^{9}$ are of the opinion that the lack of one-to-one correlation between QEEG and neuropsychologic changes may be because of the fact that deterioration in neurophysiologic function, is not necessarily responsible for a deterioration in neuropsychologic function, but rather points to the risk of suffering an unfavorable cognitive outcome. The markers of neurologic injury may also measure different endpoints, namely neuropsychologic function, electrophysiologic function, chemical marker elevation, magnetic resonance imaging changes, stroke, or death. These complexities may explain the divergent findings in previous studies. ${ }^{31}$ and 32 No awareness was reported despite no additional midazolam in the sufentanil group and the low concentration of isoflurane needed. The question must, however, be asked if a lack of recall after cardiac surgery implies adequate anesthesia because amnesia also occurs after minor brain injury.

This study has several shortcomings. The combination of anesthetic drugs makes it difficult to separate the neuroprotective effects (if any). The authors considered it unethical to administer ketamine without midazolam and to withhold an inhalation agent when clinically necessary. Animal studies do not pose this problem. A sample consisting of patients scheduled for only 1 type of surgery might have been more informative regarding a drug effect. QEEG recordings using more leads, recordings at 3 months or 6 months postoperatively, and the inclusion of neuropsychologic tests would have broadened the scope of this study.

In conclusion, by using QEEG changes as a marker, this study was unable to show a difference between sufentanil-based and ketamine and midazolam-based anesthetic techniques regarding neurologic injury after cardiac surgery in humans. 


\section{References}

1 P.J. Shaw, D. Bates and N.E. Cartlidge et al., Neurologic and neuropsychological morbidity following major surgery Comparison of coronary artery bypass and peripheral vascular surgery, Stroke 18 (1987), pp. 700-707.

2 E. Spandou, G. Karkavelas and V. Soubasi et al., Effect of ketamine on hypoxic-ischemic brain damage in newborn rats, Brain Res 819 (1999), pp. 1-7.

3 N.A. Anis, S.C. Berry and N.R. Burton et al., The dissociative anesthetics ketamine and phencyclidine selectively reduce excitation of central mammalian neurons by $\mathrm{N}$-methyl-aspartate, $\mathrm{Br} \mathrm{J}$ Pharmacol 79 (1983), pp. 565-575.

4 D.W. Choi and V. Viseskul, Opioids and nonopioid enantiomers selectively attenuate N-methyl-D-aspartate neurotoxicity on cortical neurons, Eur J Pharmacol 155 (1988), pp. 27-35.

5 A. Rubaj, K. Gustaw and W. Zgodzinski et al., The role of opioid receptors in hypoxic preconditioning against seizures in brain, Pharmacol Biochem Behav 67 (2000), pp. 65-70.

$6 \mathrm{H}$. Ito, Y. Watanabe, A. Isshiki and H. Uchino, Neuroprotective properties of propofol and midazolam, but not pentobarbital, on neuronal damage induced by forebrain ischemia, based on the $\mathrm{GABA}_{\mathrm{A}}$ receptors, Acta Anaesthesiol Scand 43 (1999), pp. 153162.

7 J.W. Olney, J. Labruyere and G. Wang et al., NMDA antagonist neurotoxcicity mechanism and prevention, Science 254 (1991), pp. 1515-1518.

8 I. Toner, K.M. Taylor and S. Newman et al., Cerebral functional changes following cardiac surgery Neuropsychological and EEG assessment, Eur J Cardiothorac Surg 13 (1998), pp. 13-20.

9 R.J. Chabot, L.D. Gugino and L.S. Aglio et al., QEEG and neuropsychological profiles of patients after undergoing cardiopulmonary bypass surgical procedures, Clin Electroencephalogr 28 (1997), pp. 98-105.

10 T. Akerstedt, L. Torsvall and M. Gillberg, Sleepiness in shift work. A review with emphasis on continuous monitoring of EEG and EOG, Chronobiol Int 4 (1987), pp. 129-140.

11 P.M. Lauven and P.J. Kulka, Anaesthesia techniques for midazolam and flumazenil-An overview, Acta Anaesthesiol Scand 92 (1990) (Suppl), pp. 84-89.

12 P.F. White, W.L. Way and A.J. Trevor, Ketamine-Its pharmacology and therapeutic use, Anesthesiology 56 (1982), pp. $119-136$.

13 A.M. Zurick, G.F. Khoury and F.G. Estafanous et al., Sufentanil requirements of surgical anesthesia (as determined by EEG) and its effects on awakening time, Anesth Analg 62 (1983), p. 292.

14 J.G. Bovill, P.J. Warren and J.L. Schuller et al., Comparison of fentanyl, sufentanil, and alfentanil anesthesia in patients undergoing valvular heart surgery, Anesth Analg 63 (1984), pp. 1081-1086.

$15 \mathrm{H}$. Sungurtekin, W. Plöchl and D.J. Cook, Relationship between cardiopulmonary bypass flow rate and cerebral embolization in dogs, Anesthesiology 91 (1999), pp. 1387-1393.

16 W.J. Hofsté, C. A.M. Linssen and E.H.J.F. Boezeman et al., Delirium and cognitive disorders after cardiac operations Relation to pre- and intraoperative quantitative electroencephalogram, Int J Clin Monit Comput 14 (1997), pp. 29-36.

17 L.D. Gugino, L.S. Chabot and L.S. Aglio et al., QEEG and neuropsychological profiles of patients prior to undergoing cardiopulmonary bypass surgical procedures, Clin Electroencephalogr 28 (1997), pp. 87-97.

18 M.F. Newman, J.L. Kirchner and B. Phillips-Bute et al., Longitudinal assessment of neurocognitive function after coronary artery bypass surgery, N Engl J Med 344 (2001), pp. 395-402.

19 L.S. Rasmussen, K. Larsen and P. Houx et al., The assessment of postoperative cognitive function, Acta Anaesthesiol Scand 45 (2001), pp. 275-289.

20 D.A. Stump, Selection and clinical significance of neuropsychological tests, Ann Thorac Surg 59 (1995), pp. 1340-1344. 
$21 \mathrm{H}$. Eilers and P.E. Bickler, Hypothermia and isoflurane similarly inhibit glutamate release evoked by chemical anoxia in rat cortical brain slices, Anesthesiology 85 (1996), pp. 600-607.

22 R. Koorn, R.A. Kahn and T.S. Brannan et al., Effect of isoflurane and halothane on in vivo ischemia-induced dopamine release in the corpus striatum of the rat, Anesthesiology 79 (1993), pp. 827-835.

23 T.J.J. Blanck, M. Haile and F. Xu et al., Isoflurane pretreatment ameliorates postischemic neurologic dysfunction and preserves hippocampal $\mathrm{Ca}^{2+} /$ calmodulin-dependent protein kinase in a canine cardiac arrest model, Anesthesiology 93 (2000), pp. $1285-1293$.

24 P. Kienbaum, T. Heuter and M.C. Michel et al., Racemic ketamine decreases muscle sympathetic activity but maintains the neural response to hypotensive challenges in humans, Anesthesiology 92 (2000), pp. 94-101.

25 T. Sakai, T. Ichiyama and C.W. Whitten et al., Ketamine suppresses endotoxin-induced NF-kB expression, Can J Anesth 47 (2000), pp. 1019-1024.

26 A.S. Baldwin Jr, The NF-kB and I kB proteins New discoveries and insights, Annu Rev Immunol 14 (1996), pp. 649-683.

27 M. Shaaban Ali, M. Harmer and R.S. Vaughan et al., Changes in cerebral oxygenation during cold $\left(28^{\circ} \mathrm{C}\right)$ and warm $\left(34^{\circ} \mathrm{C}\right)$ cardiopulmonary bypass using different blood gas strategies (alpha-stat and pH-stat) in patients undergoing coronary artery bypass surgery, Acta Anaesthesiol Scand 48 (2004), pp. 837-844.

28 S.M. Browne, P.W. Halligan and D.T. Wade et al., Postoperative hypoxemia is a contributory factor to cognitive impairment after cardiac surgery, J Thorac Cardiovasc Surg 126 (2003), pp. 1061-1064.

29 R. Hemmingsen, B. Mejsholm and S. Vorstrup et al., Carotid surgery, cognitive function, and cerebral blood flow in patients with transient ischemic attacks, Ann Neurol 20 (1986), pp. 13-19.

30 S.C. Knipp, N. Matatko and H. Wilhelm et al., Evaluation of brain injury after coronary artery bypass grafting. A prospective study using neuropsychological assessment and diffusion-weighted magnetic resonance imaging, Eur J Cardiothorac Surg 25 (2004), pp. 791-800.

31 N.A. Nussmeier, C. Arlund and S. Slogoff, Neuropsychiatric complications after cardiopulmonary bypass Cerebral protection by a barbiturate, Anesthesiology 64 (1986), pp. 165-170.

32 J.R. Zaidan, A. Klochany and W.M. Martin et al., Effect of thiopental on neurologic outcome following coronary bypass grafting, Anesthesiology 74 (1991), pp. 406-411. 